as peer-to-peer learning between reserves. The capacitybuilding programme in China has provided support to 35 nature reserves, helping them to deliver improved conservation action for more than 25 threatened tree species.

To complement the work carried out through projects the Global Trees Campaign has launched a series of technical guidance briefs promoting best practice for tree conservation. Each brief covers a different core skill for tree conservation and has been tailored to meet the needs of non-specialists (people with some experience in conservation but with limited knowledge and experience in botany, forestry or horticulture). The first series of nine briefs is available at www.globaltrees.org/resources/practical-guidance and contains guidance on carrying out tree surveys, botanical identification, monitoring, nursery management, seed collection, seed processing and storage, germination and seedling growth, germination experiments, and tree planting.

Briefs will be translated into a number of languages during 2014-2015, making them accessible to as wide an audience as possible. Because these briefs represent an introduction to tree conservation techniques, links to sources of further guidance are included. Users are encouraged to adapt the guidance to local circumstances and to approach local experts or the Global Trees Campaign for additional advice. Feedback on the briefs is welcomed (please address to david.gill@fauna-flora.org).

David Gill, Georgina Magin and Robin Loveridge Global Trees Campaign, Fauna \& Flora International, Cambridge, UK E-mail david.gill@fauna-flora.org

\section{New evidence of wild Amur tigers and leopards breeding in China}

On 15 November 2013 CCTV news reported that pug-marks of a wild adult female Amur tiger Panthera tigris altaica and three kittens had been found in the Hunchun forest department of Jilin Province in north-east China. The front pad widths of the adult were $9.0-9.3 \mathrm{~cm}$ and those of the kittens were $6.0-6.2 \mathrm{~cm}$. Experts have examined the details of the pug-marks and tracks and have confirmed the presence of a female and kittens. From the size of the pugmarks it is estimated the kittens were 4-5 months old. It is particularly notable that this record was outside Hunchun Nature Reserve, $>20 \mathrm{~km}$ away from the SinoRussian border. In recent years camera-traps have recorded adult Amur tigers in this area and local people have reported sightings of Amur tiger pug-marks and/or loss of livestock.

Historically, the Endangered Amur tiger was distributed across most of the forested montane areas of north-east China. It has been argued that this subspecies originated in China (The World's Cat (1976), 1-14) and this has been partially confirmed by a genetic study (PLoS Biology (2004),
2(12), e442). It is estimated that in the mid 2oth century there were 150 Amur tigers in China and 30-40 in Russia. However, until now, it was presumed that the c. 20 extant Amur tigers in China were migrants from the Russian far east and that it was unlikely any were resident breeding females.

There is also new evidence of the Critically Endangered Amur leopard Panthera pardus orientalis in this area. In October 2013 CCTV news reported a video recording of a female Amur leopard and two kittens walking past a video trap in the Jilin Wangqing Nature Reserve. Based on the kittens' body size it is estimated they were $<5$ months old and thus still lactating. As the area of Wangqing Nature Reserve is $>600 \mathrm{~km}^{2}$ it is most likely that this family is part of a resident population rather than being migrant. Russian wildlife biologists reported that only c. 50 extant Amur leopards were known in the Russian far east in 2012. Only 7-12 were believed to be present in China in 2000, although this estimate was derived from data collected during a survey for the Amur tiger.

Given these recent sightings and sign observations we believe the future outlook for these two subspecies in China is improving. In $2011 \mathrm{WWF}-\mathrm{China}$ initiated a prey recovery project in north-east China and introduced SMART technology (Integrative Zoology (2010), 5, 363-377) for patrolling. These measures will ensure improved habitat conditions and more effective protection for both species. The Feline Research Center of the Chinese State Forestry Administration has initiated camera-trap monitoring for both species, DNA analysis of faecal samples, and a new pug-mark identification technique in collaboration with Wildtrack. The Chinese State Forestry Administration is now consulting with experts to develop a Chinese Big Cat Conservation Action Plan to ensure the continued protection of the Amur tiger and leopard in China.

GUANGSHUN JANG Jinzhe Qi Feline Research Center of Chinese State Forestry Administration, Northeast Forestry University, Harbin, China.E-mail jgshun@126.com

\section{Indexing for Life: improved genetic data resources for conservation}

In setting conservation priorities for a taxon a range of factors need to be considered, including threatened status, endemicity, rarity, charisma, function in ecosystem and genetic diversity. When trying to determine which strategy will conserve the greatest extent of independent evolutionary life, phylogenetic distance methods can be used as they reveal the genetic uniqueness of a taxon. The evolutionary distinctiveness measure, for example, can be calculated for groups of taxa, of different Eukaryotic kingdoms, based on the length of each branch of a phylogenetic tree. By combining evolutionary distinctiveness (ED) with the 